\title{
Editorial
}

\author{
Stan Dicks \\ North Carolina State University
}

For over five years, T. R. Girill has masterfully handled the job as Editorin-Chief of this journal. His act will definitely be a hard one to follow. The journal has consistently grown bigger and more interesting during his tenure. He has worked hard to ensure that a good mix of new articles, reprinted classical articles, and book reviews challenged us in each year's issues. He has worked with Assistant Editors to help recruit commentators for the lead article in each issue. He has served as a liaison with the STC, by providing abstracts for inclusion in their journal, Technical Communication. And he has performed all of the "behind-the-scenes" jobs associated with publishing four issues of a journal each year. T. R. is an artist of the editorial "nag," encouraging Assistant Editors and authors to submit manuscripts by the deadlines with a compelling mixture of encouragement and insistence, which somehow always appealed to one's senses of responsibility, honor, and guilt. I hope that I can do as much as he has done to continue improving the journal and to maintain good relations with authors, editors, members, and other organizations.

We should also recognize the contributions of Susan Jones at MIT as Production Editor for the last five-plus years. Susan has managed to get the issues to press as fast as possible, despite the occasional bureaucratic, copyright, and file format hurdles thrown in her way.

\section{About This Issue}

Just to demonstrate what a good job T. R. and Susan have done, we have had some transition difficulties associated with getting this first issue out. Our primary problem was finding commentators quickly enough for the winning graduate student essay. It is always a scramble to publish the issue containing the graduate student winning essay, as it is not announced until the conference in the fall. This year our problems were exacerbated by the fact that we could not find willing commentators fast enough to cover the essay subject, which concerns the usability of hypertext fiction. Hence, we are publishing the article without commentaries. The literature awareness essay in this issue studies some of the problems associated with an online, collaborative, authoring effort. Just to prove that we have a sense of humor, the article covers our own efforts to arrive at a new mission statement. 


\section{About the May Issue}

The next issue will commemorate the $25^{\text {th }}$ year of this journal's publication. Included will be articles from five previous and current Chairs of the organization. These articles will cover details about the history of SIGDOC, its growth, the computer documentation industry at the time each person was chair, and other issues they think will interest us. Included will be Joe Rigo's fascinating description of how the journal came to have the asterisk in its title.

\section{Call for Submission}

We welcome your submissions of articles, awareness essays, book reviews, commentaries, and letters. For more details, see the Instructions for Authors section at the back of the journal. We especially welcome new article submissions on articles related to new and emerging computer documentation issues. Awareness essays provide an opportunity to publish shorter articles about ongoing research, about new or innovative ideas, or about subjects that do not warrant full article treatment. We would like to develop a backlog of such essays, so please write about what you have been doing or thinking and submit it as an essay.

\section{About the New Editor}

It was with some trepidation that I accepted the position as Editor-in-Chief, due in part to the hard work that I saw T. R. Girill and Susan Jones engage in to get each issue out. However, I hope that my dual careers (some would say leading to schizophrenia) in academia and industry will bring both perspectives to making editorial selections for the journal. My undergraduate degree is from UNC-Chapel Hill and my masters and Ph.D. are from Ohio University. After teaching for several years and getting tenure, I resigned and went to work as a technical communicator. For the next sixteen years, I wrote and/or managed groups writing hardware documents, software documents and help systems, proposals, training materials including multimedia, electronic performance support systems, and virtual reality environments for companies involved in the instrumentation, power generation, and telecommunication industries. Four years ago I decided to return to academia, where I now teach and direct the masters in technical communication program at NC State.

While I do not plan any radical changes to the journal, I do welcome your ideas about ways that we can improve it and make it more responsive to your needs. Please feel free to send mail, email, or to call with your input. 